\title{
Evasão na EJA: um desafio histórico
}

\author{
FERNANDES, Ana Paula Cunha dos Santos (Brasil, Pará, Belém) ${ }^{1 *}$ \\ OLIVEIRA, Iranildo da Silva (Brasil, Pará, Belém) ${ }^{1+*}$ \\ ${ }^{1}$ Universidade do Estado do Pará \\ ORCID ID: https://orcid.org/0000-0003-1934-9221 \\ ORCID ID: https://orcid.org/0000-0001-6435-2687*
}

\begin{abstract}
Resumo
Este artigo é uma pesquisa de campo e objetiva analisar quais possíveis fatores estão contribuindo para a evasão da Educação de Jovens e Adultos em uma escola estadual no município de Santa Maria do Pará. Busca-se responder à seguinte questão: quais os possíveis fatores que contribuem para a evasão da Educação de Jovens e Adultos na escola estadual de Santa Maria do Pará? Realizaram-se entrevistas com alunos, professores, uma vice-diretora e especialista em educação. Os resultados foram: ausência de um currículo que leve em consideração a especificidade do público da referida modalidade de educação; falta de segurança no ambiente de ensino e em sua localidade; falta de projetos que sivam como atrativo para os discentes; professores mais comprometidos com a educação; maior matrícula do público feminino; entre outros.
\end{abstract}

Palavras-chave

Educação de Jovens e Adultos. Evasão. Educação. Práticas pedagógicas.

\section{Evasion at EJA: an historic challenge}

\begin{abstract}
This article is a field research and aims to analyze what possible factors are contributing to the dropout of Education of Youth and Adults in a state school in Santa Maria do Pará. It seeks to answer: what are the possible factors that contribute to the avoidance of Education of Youth and Adults in the state school of Santa Maria do Pará? Interviews were conducted with students, teachers, a deputy principal and education specialist. The results were: absence of a curriculum that takes into account the specificity of the public of the Education of Youth and Adults; lack of safety in the teaching environment and in its locality; lack of projects that serve as an attraction for students; teachers more committed to education; there is greater enrollment of the female audience; among others.
\end{abstract}

\section{Keywords}

Education of Youth and Adults. Evasion. Education. Pedagogical practices.

\section{Evasión en la EJA: un desafío histórico}

\section{Resumen}

Este artículo es una investigación de campo y tiene como objetivo analizar qué posibles factores están contribuyendo al abandono de la Educación de Jóvenes y Adultos en una escuela estatal en Santa Maria do Pará. Se busca responder la siguiente cuestión: ¿cuáles son los posibles factores que contribuyen a la
} 
evasión de la Educación de Jóvenes y Adultos en la escuela estatal de la ciudad Santa Maria do Pará? Se realizaron entrevistas con estudiantes, maestros, subdirector y especialista en educación. Los resultados fueron: ausencia de un currículo que tenga en cuenta la especificidad del público de la Educación de Jóvenes y Adultos; falta de seguridad en el ambiente de enseñanza y en su localidad; falta de proyectos que sirvan como atractivos para los alumnos; profesores más comprometidos con la educación; mayor matrícula del público femenino; entre otros.

\section{Palabras clave}

Educación de Jóvenes y Adultos. Evasión. Educación. Prácticas pedagógicas.

\section{INTRODUÇÃO}

Objetiva-se, neste artigo, analisar quais possíveis fatores estão contribuindo para a evasão da Educação de Jovens e Adultos (EJA) em uma escola estadual no município de Santa Maria do Pará. Este artigo utilizou a pesquisa de campo e é um recorte da pesquisa de mestrado em Educação. Este texto está organizado da seguinte maneira: "Uma breve apresentação", "Metodologia", "A EJA, a escola e a evasão" e "Considerações finais".

\section{UMA BREVE APRESENTAÇÃO}

A EJA tem levantado várias reflexões pertinentes, como: alfabetização de jovens e adultos (FREIRE, 2000); formação de professores para a EJA e discussão sobre 0 currículo da EJA (MACHADO, 2008); legislação para a EJA (UNESCO, 2008), entre outras, levando-se a questionar sobre a prática pedagógica adotada pelas instituições de ensino em sua aplicabilidade na modalidade EJA. Assim, acredita-se que o aluno da EJA necessita de práticas pedagógicas concretas e atrativas de aprendizagem que possam influenciar no processo de construção do conhecimento para que futuramente não venha a ocasionar a evasão da EJA.

Em busca de encontrar os motivos que levam ao abandono escolar, surge o questionamento: o que está contribuindo para a evasão na EJA de uma escola estadual no município de Santa Maria do Pará? Assim, busca-se analisar quais os possíveis fatores que contribuíram para a evasão da EJA em uma escola estadual no município de Santa Maria do Pará. Ressalta-se que o alunado dessa instituição é composto por 
trabalhadores das mais variadas áreas (pedreiros, donas do lar, agricultores, entre outras), residindo uma grande maioria na zona rural do município.

Segundo a proposta curricular para a EJA (BRASIL, 2002, p. 87), tal modalidade tem função histórico-político-social, pois sua finalidade é "reparar, equalizar e qualificar", para que seu público-alvo se torne cidadão crítico-reflexivo de seus direitos como cidadãos construtores de opiniões. É notório que tais alunos necessitam desses direitos, e uma maneira para a sua reparação é dando-Ihes oportunidade de ensino, tendo-se os educandos como peças-chave no processo de construção do conhecimento, equalizando-os para que sejam inseridos no mercado de trabalho e para que permaneçam e se desenvolvam com níveis aceitáveis e com uma formação de excelência não só no campo educacional, mas em todos os aspectos, visto que a EJA com essas funções evidencia um desafio histórico.

No levantamento sobre as produções na área feito no Banco de Teses da Coordenação de Aperfeiçoamento de Pessoas de Nível Superior (Capes), o qual dispõe de publicações de dissertações e teses de programas de pós-graduação do país desde 1987, foram usados os seguintes descritores: "evasão na EJA"; "evasão na Educação de Jovens e Adultos"; "evasão escolar na EJA"; e "EJA e a evasão". Dentro desses descritores, foram encontradas apenas 17 produções condizentes com o tema, sendo que foram encontrados 21 trabalhos referentes à temática.

Dentre os pesquisados, evidenciou-se o quantitativo de 17, dos quais foram destacados: 1) Educação de Jovens e Adultos: perspectivas e evasão no município de Cáceres-MT (LARA, 2011); 2) Educação de Jovens e Adultos e a evasão escolar: o caso do Instituto Federal do Ceará, campus de Fortaleza (ROCHA, 2011); 3) Educação de Jovens e Adultos na cidade de Natal: uma reflexão sobre insucesso e sucesso (NOGUEIRA, 2012); 4) Educação de Jovens e Adultos: um estudo sobre trajetórias escolares interrompidas (SANTOS, 2012).

\section{METODOLOGIA}

A metodologia utilizada para este estudo foi de cunho investigativo, por meio de pesquisa de campo. Sobre isso, Fonseca (2002, p. 20) relata que "[...] a pesquisa de campo se caracteriza pelas investigações em que, além da pesquisa bibliográfica e/ou 
documental, se realiza coleta de dados junto a pessoas, com o recurso de diferentes tipos de pesquisa".

A pesquisa foi realizada no município de Santa Maria do Pará, nordeste do estado do Pará, cerca de 100 quilômetros de distância de Belém (capital do estado), com uma população de aproximadamente 23.033 habitantes, de acordo com o Censo de 2010 do Instituto Brasileiro de Geografia e Estatística (IBGE, 2011), com uma taxa alarmante de $26,1 \%$ de analfabetos com 15 anos ou mais. A escola está situada no Centro da cidade, mas em uma área considerada periférica, atendendo a um público residente na zona urbana e rural do município.

Ao analisar o Projeto Político-Pedagógico (PPP) da instituição (2012), o mais atual que a escola disponibilizava então, verificou-se que a unidade escolar constitui-se por dez salas, uma diretoria, uma secretaria, uma sala de professores, uma biblioteca, uma sala de informática, um depósito de material de limpeza, uma dispensa, um refeitório, uma quadra de esportes coberta, uma cozinha, uma área de serviço, uma sala multifuncional, uma sala da coordenação pedagógica, dois banheiros para funcionários, quatro banheiros para alunos (divididos entre homens e mulheres) e dois banheiros para cadeirantes. No quadro de funcionários, a escola contava no referido ano com 51, distribuídos entre professores, equipe técnica, direção, vigias e serventes, sendo 46 efetivos e cinco contratados.

Para a coleta de dados, foram necessários cinco dias, a saber: 28 de novembro e 1ㅇ, 4, 5 e 10 de dezembro de 2014. As entrevistas com alunos, professores, uma vice-diretora e especialista em educação foram realizadas no turno da noite, sendo que a diretora e o vice-diretor foram entrevistados no turno da manhã. No referido ano, a EJA estava distribuída da seguinte maneira: uma turma de $1^{\text {a }}$ Etapa (1 $1^{\text {a }}$ e $2^{\underline{a}}$ séries); uma

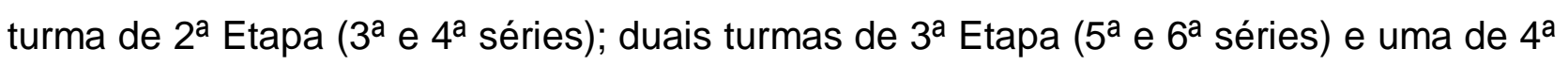
Etapa ( $7^{\mathrm{a}}$ e $8^{\mathrm{a}}$ séries). Dentro disso, 203 estudantes foram matriculados no ano de 2014.

Tabela 1 - Alunos matriculados na EJA em 2014

\begin{tabular}{lcccccc}
\hline Situação & $\mathbf{1}^{\text {a Etapa }}$ & $\mathbf{2}^{\text {a }}$ Etapa & $\mathbf{3}^{\mathrm{a}}$ Etapa “A" & $\mathbf{3}^{\mathrm{a}}$ Etapa "B" & $\mathbf{4}^{\mathrm{a}}$ Etapa & Total \\
\hline Matriculados & 25 & 30 & 50 & 45 & 53 & 203 \\
\hline Frequentando & 10 & 08 & 09 & 15 & 21 & 63 \\
\hline
\end{tabular}

Fonte: Elaborada pelos autores com dados obtidos na escola lócus (2014). 
Os dados ilustrados na Tabela 1 representam os discentes que foram matriculados no início do ano letivo (janeiro) e os que havia no final do mesmo ano (dezembro); do total de 203 matriculados, desistiram 140 educandos.

Com o intuito de preservar a identidade dos docentes entrevistados, seus nomes foram substituídos por P1, P2, P3..., etc. A escola contava com um número reduzido de profissionais trabalhando no turno da noite, turno em que funciona a EJA.

As informações seguintes foram resultadas das respostas coletadas dos entrevistados no quesito aluno; para uma melhor ilustração, estão distribuídas na forma de tabela.

Tabela 2 - Distribuição dos alunos relacionando idade e sexo

\begin{tabular}{ccc}
\hline Idade & Masculino & Feminino \\
\hline $\mathbf{1 5 - 2 0}$ & 12 & 10 \\
$\mathbf{2 1 - 3 0}$ & 03 & 06 \\
$\mathbf{3 1 - 4 0}$ & - & 03 \\
$\mathbf{4 1}$ ou mais & 02 & 02 \\
\hline Total & 17 & 21
\end{tabular}

Fonte: Elaborado pelos autores com dados obtidos na escola lócus (2014).

Havia maior quantitativo de pessoas do sexo masculino na faixa etária de 15-20 anos, mas no total havia um maior número de pessoas do sexo feminino. O público de menor expressividade foi o da faixa etária de 41 ou mais.

Tabela 3 - Amostra dos entrevistados em relação às perguntas propostas para conhecer o público que frequentava a escola pesquisada

\begin{tabular}{ccccc}
\hline Perguntas & \multicolumn{2}{c}{ Homem } & \multicolumn{2}{c}{ Mulher } \\
\cline { 2 - 5 } & Sim & Não & Sim & Não \\
Trabalho & 17 & - & 13 & 08 \\
Vida conjugal & 04 & 13 & 05 & 16 \\
Filhos & 03 & 14 & 08 & 13 \\
Renda familiar até um salário & 07 & 08 & 06 & 15 \\
Renda familiar maior do que um & 08 & 07 & 07 & 14 \\
salário & 13 & 04 & 15 & 06 \\
Bolsa Família &
\end{tabular}

Fonte: Elaborado pelos autores com dados obtidos na escola lócus (2014).

Percebeu-se que todos os homens trabalhavam e que mais da metade das mulheres possuíam atividade laboral. Em geral, as mulheres já possuem filhos, trabalham fora e em casa, compondo dupla ou tripla jornada. Mesmo todos os homens 
respondendo que trabalhavam, quase todos disseram receber Bolsa Família, mostrando um resultado próximo ao de mulheres que recebiam o incentivo do governo.

Gráfico 1 - llustração de alunos da EJA matriculados, evadidos e concluintes nos anos de 2011-2014

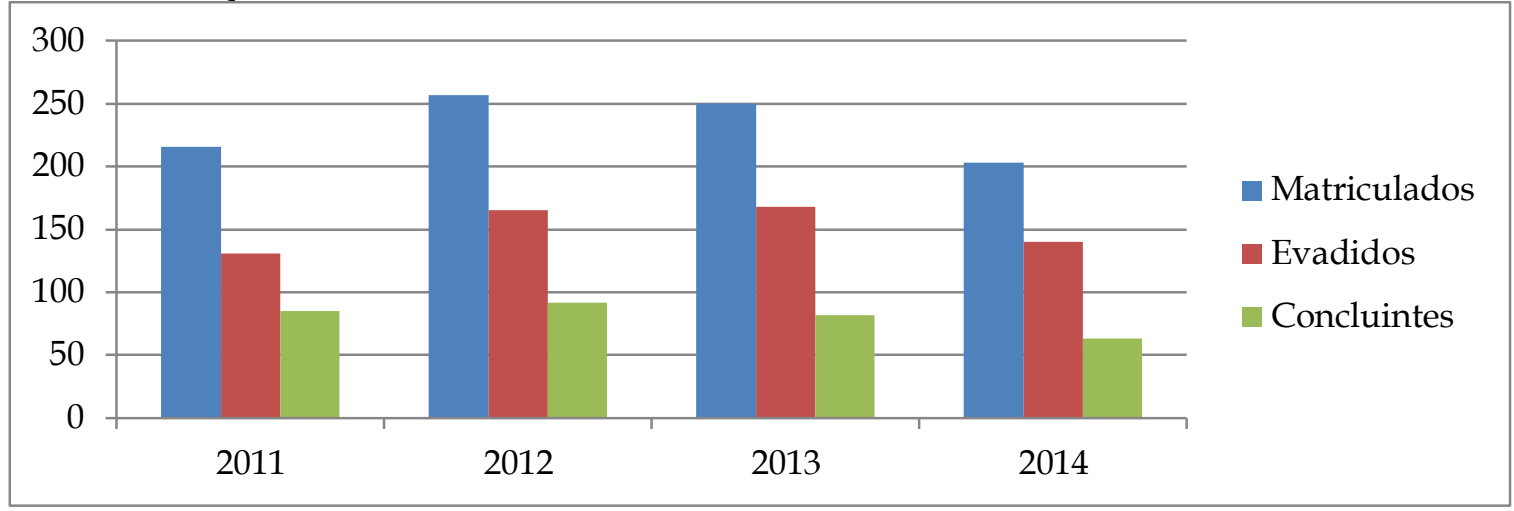

Fonte: Elaborado pelos autores com dados obtidos na escola lócus (2014).

Segundo os dados obtidos no lócus da pesquisa, torna-se evidente que a questão da evasão na escola pesquisada não diz respeito unicamente ao período da pesquisa, visto a existência de um processo contínuo e crescente de abandono que vem se perpetuando ao longo dos anos.

Tabela 4 - A evasão na EJA em percentual nos anos de 2011-2014

\begin{tabular}{lc}
\hline Ano & Percentual de desistência \\
\hline $\mathbf{2 0 1 1}$ & $60,7 \%$ \\
$\mathbf{2 0 1 2}$ & $64,4 \%$ \\
$\mathbf{2 0 1 3}$ & $67,2 \%$ \\
$\mathbf{2 0 1 4}$ & $68,9 \%$ \\
\hline
\end{tabular}

Fonte: Elaborado pelos autores com dados obtidos na escola lócus (2014).

Por meio desses dados, são perceptíveis os números alarmantes da evasão na escola, transformando-se em um processo histórico dentro do cenário em que se encontra essa instituição de ensino, pois provavelmente a evasão na EJA não estava acontecendo desde 2011, como mostra a tabela, pondo em risco o futuro dessas pessoas e da referida modalidade de ensino na escola pesquisada.

$\mathrm{O}$ roteiro com as perguntas para os discentes foi composto por 13 perguntas, incluindo fechadas e abertas, a fim de ter-se um panorama sobre o público atendido pelo local da pesquisa. Para os profissionais da educação, foram elaboradas seis perguntas abertas, visando analisar o conhecimento que tinham sobre a modalidade. $\mathrm{O}$ destinado aos alunos envolveu questões relativas a: trabalho; vida conjugal; filho(s); renda do 
Programa Bolsa Família; renda familiar de até um salário mínimo; renda familiar maior do que um salário mínimo; depois de ter voltado a estudar, o aluno abandona a escola; situação econômica atrapalha ou dificulta o acesso aos estudos; o local de trabalho interfere em frequentar a escola; apoio da família para continuar estudando; metodologia utilizada na sala de aula; incentivos encontrados na escola para continuar estudando; e melhorias a serem implementadas na escola para atrair a atenção dos alunos.

O roteiro destinado aos docentes (incluindo especialista em educação e direção) foi composto por seis perguntas abertas, com a finalidade de se ter maiores informações a respeito dos conhecimentos dos profissionais sobre a EJA: como é organizado o currículo da EJA? O currículo garante a relação entre trabalho e educação para seus discentes? Como se materializa o currículo por meio das práticas pedagógicas? Há muita evasão na EJA em relação à escola da pesquisa e o que contribui para isso? Que métodos são aplicados para diminuir a evasão? Que projetos a longo prazo a escola propõe para minimizar os impactos da evasão escolar?

\section{A EDUCAÇÃo DE JOVENS E ADULTOS, A ESCOLA E A EVASÃo}

Nesta seção, dentre os tópicos a discutir, destacam-se: o ensino na EJA, a EJA na escola e a evasão na/da EJA. O Anuário Brasileiro da Educação Básica de 2014 apontava uma taxa de abandono no último ano do ensino fundamental de $4,1 \%$ e de $11,6 \%$ no primeiro ano do ensino médio no ano de 2012 nas escolas de todo o país, consequentemente esses jovens buscavam, de alguma forma, reparar o tempo na modalidade EJA. O mesmo anuário relatava que em 2012 o número de distorção entre idade e série chegou a $22 \%$ no ensino fundamental e $31,1 \%$ no ensino médio.

A EJA, sendo uma modalidade da educação básica, tem, entre as prioridades das prioridades, a garantia de ensino fundamental a todos os que a ele não tiveram acesso na idade própria ou que não o concluíram (BRASIL, 2010); o que é reafirmado na vigente Lei de Diretrizes e Bases da Educação Nacional (LDBEN), Lei no 9.394/1996, no artigo 37: "A Educação de Jovens e Adultos será destinada àqueles que não tiveram acesso ou continuidade de estudos no ensino fundamental e médio na idade própria".

O fato de a pessoa, jovem ou adulto, procurar a escola para dar continuidade ou começar a estudar já demonstra uma mudança de ideias sobre sua posição na 
sociedade ou vislumbra na educação uma oportunidade de mudança no seu quadro financeiro e social. Para Freire (1992), a procura desse público à escola se deve ao fato do querer decodificar a leitura e a escrita, mas pontua que tal acontecimento termina despertando consequentemente o pensamento crítico. Dentro dessa perspectiva, a escola deve estar disposta a buscar estratégias para o desenvolvimento do alunado em todas as áreas do conhecimento propostas por meio de aulas atraentes e diversificadas. Dentro dessa óptica, Gadotti (2009, p. 17) argumenta que:

A educação é necessária para a sobrevivência do ser humano. Para que ele não precise inventar tudo de novo, necessita apropriar-se da cultura, do que a humanidade já produziu. Se isso era importante no passado, hoje é ainda mais decisivo, numa sociedade baseada no conhecimento.

Nesse viés, o conhecimento de mundo do aluno da EJA está além, se comparado com o aluno do ensino regular, e busca na escola a interação com o professor para que esse conhecimento seja aprimorado na perspectiva educacional, aproveitando o conhecimento que cada um traz de casa, desenvolvendo aulas a partir do cotidiano deles. Dessa forma, os discentes se sentirão como parte do processo de ensino-aprendizado, pois estarão construindo o conhecimento. Dentro desta concepção, Freire (1967, p. 43) argumenta que:

\begin{abstract}
A partir das relações do homem com a realidade, resultantes de estar com ela e de estar nela, pelos atos de criação, recriação e decisão, vai ele dinamizando o seu mundo. Vai dominando a realidade. Vai humanizando-a. Vai acrescentando a ela algo de que ele mesmo é o fazedor. Vai temporalizando os espaços geográficos. Faz cultura. E é ainda o jogo destas relações do homem com o mundo e do homem com os homens, desafiado e respondendo ao desafio, alterando, criando, que não permite a imobilidade, a não ser em termos de relativa preponderância, nem das sociedades nem das culturas. $E$, na medida em que cria, recria e decide, vão se conformando as épocas históricas. É também criando, recriando e decidindo que o homem deve participar destas épocas.
\end{abstract}

A EJA se constrói dentro de suas especificidades, com um público diversificado, rico de conhecimentos e de diferentes culturas e camadas sociais, tais como: indígenas, negros, brancos, evangélicos, católicos, entre outras. Todos com o mesmo objetivo, procurando se identificar e permanecer dentro do espaço que para muitos não estava dentro de suas rotinas, ou seja, a sala de aula. 
A EJA tem papel fundamental na construção histórico-social na vida de seus educandos, levando em consideração o papel transformador da educação, pois, quanto mais o aluno tiver contato com o meio letrado, mais se tornará independente e crítico, então cabe ao professor selecionar e organizar aulas que estimulem a prática do pensamento crítico, para que os discentes tenham percepções distintas dos acontecimentos sociais.

Desenvolver a criticidade no alunado da EJA é exercer o empoderamento de seus direitos como cidadão, papel fundamental da escola e principalmente do professor, pois transformar esse discente em ser político, no verdadeiro sentido da palavra, é libertá-lo das amarras construídas historicamente por uma classe dominante. Arroyo (2002, p. 79) argumenta que "[...] é a esse processo educativo que a burguesia e seu Estado reagem, tentam negá-lo, desarticulá-lo, confundi-lo". As estratégias de formação de consciência devem ser pensadas pelos profissionais da educação de forma a estimular o aluno a seguir esse viés, além de contribuir para a permanência no ambiente escolar.

Nas últimas décadas, a EJA vem ganhando destaque no cenário nacional e internacional, pois, para erradicar a taxa de analfabetismo, deve-se ter um olhar mais atento para essa modalidade; pensando nisso, a Declaração de Hamburgo (UNESCO, 1999, p. 20) afirma que:

4. [...] A perspectiva de aprendizagem durante toda a vida exige, por sua vez, complementaridade e continuidade. É de fundamental importância a contribuição da educação de adultos e da educação continuada para a criação de uma sociedade tolerante e instruída, para o desenvolvimento socioeconômico, para a erradicação do analfabetismo, para diminuição da pobreza e para a preservação do meio ambiente.

Pode-se perceber que o discente da EJA, por meio do conhecimento que traz consigo, poderá se tornar ponto-chave para o processo de ensino-aprendizagem, mas, como já foi exposto anteriormente, não foi evidenciada nenhuma citação sobre a EJA ou para a EJA dentro do PPP da unidade de ensino pesquisada. Nessa óptica, Fernandes e Gonçalves (2013, p 47) afirmam que "A EJA tem sido identificada como Educação popular, e por isso tem significado. A modalidade de ensino em questão tem sido compreendida de maneira equivocada como uma ação descompromissada". Seguindo nesta vertente, Freire (1987, p. 49) conclui que: 
Esta prática implica, por isto mesmo, em que o acercamento às massas populares se faça, não para levar-lhes uma mensagem 'salvadora', em forma de conteúdo a ser depositado, mas, para, em diálogo com elas, conhecer, não só a objetividade que estão, mas a consciência que tenham desta objetividade; os vários níveis de percepção de si mesmos e do mundo em que e com que estão.

A educação ao longo da história tem sido vista como uma forma que contribui para a manutenção do poder. Em relação a essa posição, Arroyo (2002) pondera que a elite dominante sempre controlou a educação para não chegar ao ponto de o povo ficar esclarecido de sua função/posição social e questionar seus direitos, oferecendo uma educação dualista, numa concepção de aparelho reprodutor do Estado. Mas o desejo dos educandos da EJA, segundo Lara (2011, p. 66), é sempre alcançar "[...] melhores postos de trabalho, de mais qualidade de vida e melhores condições para interagir com as pessoas e com o mundo globalizado no qual estão inseridos”.

\subsection{Ensino na EJA}

Mesmo com toda a evolução no caráter de lei que veio para amenizar a forma que a EJA vem sendo abordada, chegou-se ao século XXI ainda com problemas que eram encontrados há anos. Sobre isso, P7 argumentou:

Acho que o ensino na EJA deveria ser diferenciado, porque os alunos já vêm cansados para a escola (muitos deles trabalham); deveria ser mais atraente, interessante. Deveríamos utilizar a tecnologia a nosso favor. Mas a Seduc [Secretaria da Educação] não proporciona isso; não temos cursos, apenas cobranças.

$\mathrm{Na}$ declaração do profissional $\mathrm{P} 7$, mostra-se certa preocupação quanto à formação necessária para trabalhar na EJA, além relato da inexistência de parcerias para a formação continuada, pois, só por meio de formação adequada, os professores poderão socializar o conhecimento com seus alunos de forma diferenciada. Para Arroyo (2002, p. 78), isso acontece porque:

[...] o direito à educação, os avanços das classes trabalhadoras na formação do saber, da cultura e da identidade de classe continuam sendo sistematicamente negados, reprimidos e, enquanto possível, desestruturados, por serem radicalmente antagônicos ao movimento do capital. 
Com a aquisição do conhecimento proporcionado pela educação, o aluno se fará autossuficiente em seus pensamentos, questionando o que the é imposto e tendo uma visão ampla dos problemas sociais, além de querer chegar a níveis mais elevados, pondo em risco a estabilidade da pirâmide social.

A formação do profissional é indiscutível quanto às possibilidades diversificadas no processo de ensino-aprendizagem para oferecer a quem procura essa modalidade; além disso, esse profissional deve estar preparado para trabalhar na EJA. Machado (2010, p. 115) considera que:

O desafio pedagógico de reconhecimento da nossa intransponível incompletude é por demais contraditório com a lógica 'acadêmica', que nos vende uma falsa ideia de verdade que pode ser apanhada e aprisionada numa capacitação, num treinamento, ou como ainda infelizmente muitos costumam chamar, numa 'reciclagem'.

A autora pontua sobre a formação dos profissionais da educação, sendo necessária uma formação/qualificação para todos os profissionais, visando sempre expandir o conhecimento dentro da área escolhida.

\subsection{A EJA na escola}

A EJA é uma modalidade de conquista social, mas a evasão vem contribuindo para o esvaziamento das salas de aula da escola lócus da pesquisa. Ao analisar o documento que norteia as ações dentro das instituições de ensino, sendo o PPP responsável por direcionar as atividades nas modalidades atendidas na escola em questão, não foi evidenciado nenhum parágrafo que inserisse a EJA nas atividades da escola ou nas metas que essa instituição deveria atingir, como é a questão da evasão escolar. O PPP mais atual da escola datava do ano de 2012, o qual não englobava a EJA, tornando-se evidente não ser um compromisso dos gestores da escola, pois todos os projetos que nele se encontravam estavam voltados para o ensino regular. 


\subsection{A evasão na/da EJA}

A evasão é um dos maiores percalços no desenvolvimento do aluno jovem ou adulto que, por diversos fatores, internos e/ou externos à escola, foram levados ao abandono escolar. E esse problema deve ser conduzido com seriedade para que futuras turmas ou até mesmo a modalidade EJA não acabe por falta de alunos e/ou projetos que visem à garantia de permanência no recinto educacional. Nogueira (2012) acrescenta que o problema da evasão na EJA não é local ou regional, e sim um problema em todo o país, problema esse histórico.

Perguntou-se aos alunos e profissionais da educação os motivos que haviam levado os discentes a se evadirem da EJA. Segundo os profissionais da educação entrevistados, os motivos foram: falta de segurança; localização da escola; direção escolar; professores; falta de projetos que despertassem o interesse dos educandos em permanecer no ambiente escolar; emprego; gravidez; e falta de interesse dos próprios estudantes. $O$ que deve ser evidenciado é que $80 \%$ dos profissionais entrevistados apontaram como o principal fator que contribuía para o esvaziamento das salas de aula a falta de segurança, já $50 \%$ relataram que a localização da escola era um dos principais.

Os locais menos abastados do município recebem consequentemente menos visibilidade do poder público, além de atender a uma clientela menos favorecida economicamente. Isso, somado à pouca iluminação e à ausência de auxílio policial, acarreta o favorecimento à criminalidade.

Para os alunos, os motivos foram parecidos, a saber: falta de segurança; falta interesse dos estudantes; respeito da direção da escola com os estudantes; professores mais comprometidos com a educação; projetos que despertem o interesse dos discentes em permanecer na escola. Podendo ser ilustrado da seguinte maneira: $41,8 \%$ dos alunos revelaram que a falta de segurança contribuía para o desaparecimento dos discentes na referida escola na modalidade EJA; $10,52 \%$ afirmaram que faltava mais respeito na forma da direção tratá-los; outros $10,52 \%$ relataram que sentiam falta de interesse maior dos professores para com os alunos; e 37,16\% não souberam ou não opinaram sobre o que contribuía para o sumiço dos discentes da sala de aula.

A falta de segurança era o maior agravante e estava colaborando diretamente para que os estudantes deixassem de frequentar a escola; dentre as evidências, a 
referida instituição localiza-se em um bairro periférico, alheio aos olhos do poder público, pois discentes da escola já haviam relatado alguns assaltos na localidade; além disso, a falta de iluminação pública tornava o ambiente propício para tais delitos. No tocante a essa temática, Santos (2012, p. 102) conclui que: "[...] a exclusão escolar encontra acento na raiz da exclusão social, marcada pela contradição de classes num modelo econômico também desigual", visto que:

As práticas de Educação de Adultos nasceram no seio da sociedade civil, das 'lacunas' do Sistema Educacional Brasileiro. As principais características das ações governamentais em EJA no século XX foram de políticas assistencialistas, populistas e compensatórias. (ROCHA, 2011, p. 24).

Em meio a tantos problemas sociais existentes que, de alguma forma, interferem/impedem o público da EJA a se escolarizar, quando tais alunos, por decisão própria, buscam as instituições de ensino para ampliar seus conhecimentos, o mínimo que poderia ser oferecido seria uma educação de qualidade, visando aos níveis mais elevados do conhecimento.

\section{CONSIDERAÇÕES FINAIS}

O objetivo deste trabalho foi analisar, por meio de pesquisa de campo, os fatores que contribuem para a evasão da EJA em uma escola estadual de Santa Maria do Pará. A temática EJA destaca a problemática da evasão escolar, mesmo com leis mais flexíveis dando condições do ingresso e permanência nas instituições. Dentre os resultados encontrados, elenca-se que: no ano de 2014, apenas 63 alunos concluíram o ano letivo, representando a evasão escolar o percentual de $68,96 \%$ dos estudantes matriculados na instituição no referido ano.

Dentro do período de 2011 a 2014, o ano de 2014 apresentou o menor quantitativo de matriculados e concluintes, 203 e 63, respectivamente. Nos anos de 2012 e 2013, houve expressivo quantitativo de matriculados, acompanhado de discentes evadidos. A evasão na EJA tem-se mostrado ao longo dos anos nos registros da secretaria e no censo da escola. O percentual de desistência/evasão, no período de 2011 a 2014, aumentou em aproximadamente 8,2\%. 
Sobre o ensino na EJA, os professores destacaram que poderia ser mais atraente, diferenciado e interessante com o uso da tecnologia a seu favor. Ressaltaram ainda a ausência de formação continuada pela Secretaria de Educação. Não constava a EJA nas atividades ou nas metas do PPP da escola. Essa ausência sugere a invisibilidade da modalidade nas ações da gestão da escola.

Dentre os fatores da evasão elencados, $80 \%$ dos professores apontaram a falta de segurança e $50 \%$ indicaram a localização da escola. Já os alunos indicaram: falta de segurança (41,8\%); ausência de respeito da direção/gestão quanto aos discentes $(10,52 \%)$; falta de interesse dos professores com os estudantes $(10,52 \%)$. Alguns discentes não opinaram ou não souberam responder (37,16\%). Registra-se que, tanto para os professores quanto para os alunos, o mais significativo foi a ausência de segurança, mas não se pode ignorar as críticas e apontamentos elencados sobre a escola, gestão, professores, ensino e outros.

\section{REFERÊNCIAS}

ARROYO, M. G. O direito do trabalhador à educação. In: GOMES, C. M. et al. (Org.). Trabalho e conhecimento: dilemas na educação do trabalhador. São Paulo: Cortez, 2002. p. 75-92.

BRASIL. Lei o 9.394, de 20 de dezembro de 1996. Estabelece as Diretrizes e Bases da Educação Nacional. Diário Oficial [da] República Federativa do Brasil, Poder Executivo, Brasília, DF, 21 dez. 1996.

BRASIL. Parecer CNE/CEB n. 6/2010. Reexame do Parecer CNE/CEB, que institui Diretrizes Operacionais para a Educação de Jovens e Adultos - EJA, nos aspectos relativos à duração dos cursos e idade mínima para ingresso nos cursos de EJA; idade mínima e certificação nos exames de EJA; e Educação de Jovens e Adultos desenvolvida por meio da Educação a Distância. Diário Oficial [da] República Federativa do Brasil, Poder Executivo, Brasília, DF, 7 abr. 2010.

BRASIL. Proposta Curricular para a educação de jovens e adultos: segundo segmento do ensino fundamental: $5^{\mathrm{a}}$ a $8^{\mathrm{a}}$ série: introdução. Brasília, DF: Ministério da Educação, 2002.

FERNANDES, A. P. C. S.; GONÇALVES, T. G. Alunos com deficiência na Educação de Jovens e Adultos: e a formação para os professores? In: RESENDE DA COSTA, M. P. (Org.). Educação especial: sugestões de recursos para os ambientes educacionais inclusivos. São Carlos: Pedro \& João, 2013. p. 29-50. 
FONSECA, J. J. S. Metodologia da pesquisa científica. Fortaleza: UEC, 2002. Apostila.

FREIRE, P. Educação como prática da liberdade. Rio de Janeiro: Paz e Terra, 1967.

FREIRE, P. Pedagogia da esperança: um reencontro com a pedagogia do oprimido. Rio de Janeiro: Paz e Terra, 1992.

FREIRE, P. Pedagogia da indignação: cartas pedagógicas e outros escritos. São Paulo: Unesp, 2000.

FREIRE, P. Pedagogia do oprimido. 17. ed. Rio de Janeiro: Paz e Terra, 1987.

GADOTTI, M. Educação de adultos como direito humano. São Paulo: Paulo Freire, 2009.

IBGE - Instituto Brasileiro de Geografia e Estatística. Censo 2010. Rio de Janeiro: IBGE, 2011.

LARA, P. J. Educação de Jovens e Adultos: perspectivas e evasão no município de Cáceres-MT. 2011. 98 f. Dissertação (Mestrado Acadêmico em Educação) - Programa de Pós-Graduação em Educação, Universidade do Oeste Paulista, Presidente Prudente, 2011.

MACHADO, M. M. (Org.). Formação de educadores de jovens e adultos. Brasília, DF: Secadi: Unesco, 2008.

MACHADO, M. M. Processos de formação de educadores de jovens e adultos: os desafios políticos e pedagógicos da formação de educadores de EJA no Brasil. In: DALBEN, Â. I. L. F. et al. (Org.). Convergências e tensões no campo da formação e do trabalho docente. Belo Horizonte: Autêntica, 2010. p. 100-121.

NOGUEIRA, A. A. S. Educação de Jovens e Adultos na cidade de Natal: uma reflexão sobre insucesso e sucesso. 2012. 68 f. Dissertação (Mestrado Acadêmico em Educação) - Programa de Pós-Graduação em Educação, Universidade Federal do Rio Grande do Norte, Natal, 2012.

ROCHA, W. M. Educação de Jovens e Adultos e a evasão escolar: o caso do Instituto Federal do Ceará, campus de Fortaleza. 2011. 157 f. Dissertação (Mestrado Acadêmico em Educação) - Programa de Pós-Graduação em Educação, Universidade Federal do Ceará, Fortaleza, 2011.

SANTA MARIA DO PARÁ. Projeto Político-Pedagógico. 2012.

SANTOS, V. P. Educação de Jovens e Adultos: um estudo sobre trajetórias escolares interrompidas. 2012. 167 f. Dissertação (Mestrado Acadêmico em Educação) Programa de Pós-Graduação em Educação, Pontifícia Universidade Católica de Goiás, Goiânia, 2012. 
TODOS PELA EDUCAÇÃO. Anuário Brasileiro da Educação Básica. São Paulo, Moderna, 2014.

UNESCO - Organização das Nações Unidas para a Educação, a Ciência e a Cultura. Declaração de Hamburgo: agenda para o futuro. Brasília, DF: Sesi/Unesco, 1999.

UNESCO - Organização das Nações Unidas para a Educação, a Ciência e a Cultura. Alfabetização de jovens e adultos no Brasil: lições da prática. Brasília, DF: Unesco, 2008.

\section{Ana Paula Cunha dos Santos Fernandes (Brasil, Pará, Belém)}

Universidade do Estado do Pará (UEPA)

Professora doutora na Universidade do Estado do Pará (UEPA) com atuação na graduação e na pós-graduação em Educação. Coordena o Grupo de Estudos e Pesquisas em Educação Especial na Amazônia (GEPEEAm).

Lattes: http://lattes.cnpq.br/8441289836978380.

E-mail: docenteapf@gmail.com.

\section{Iranildo da Silva Oliveira (Brasil, Pará, Belém)}

Universidade do Estado do Pará (UEPA)

Mestrando no Programa de Pós-Graduação em Educação na Universidade do Estado do Pará (UEPA), na Linha de Formação de Professores e Práticas Pedagógicas. Graduado em Pedagogia. Especialista em Atendimento Educacional Especializado. Atuante no Grupo de Estudos e Pesquisas em Educação Especial na Amazônia (GEPEEAm).

Lattes: http://lattes.cnpq.br/5678711232049629.

E-mail: iranildo_silva_oliveira@hotmail.com.

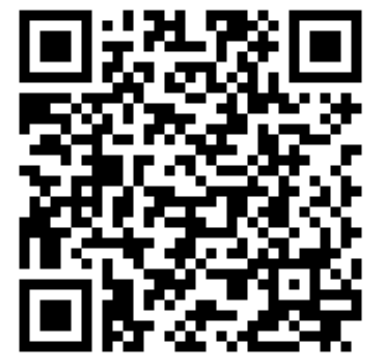

Recebido em 05 de fevereiro de 2019.

Aceito em $01^{\circ}$ de julho de 2019. 